\title{
Obituario
}

\section{Dr. Camilo José Escobar Castaño}

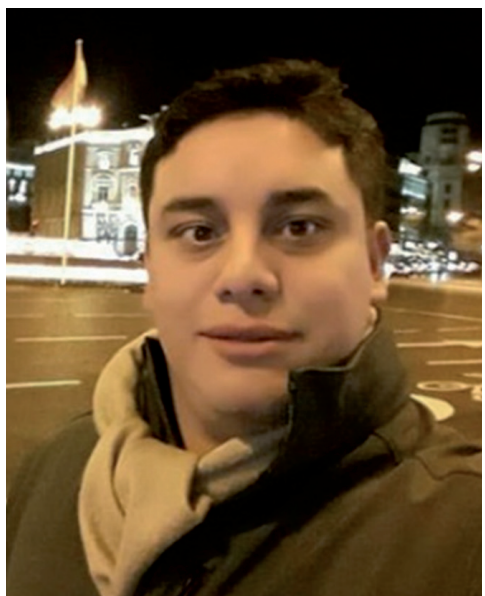

30 de noviembre de 1989

† 22 de agosto de 2020

Sin lugar a dudas una de las personas más virtuosas que hemos conocido, el Dr. Camilo Escobar deja un vacío importante en la vidas de cada una de los que tuvimos el privilegio de compartir con él, dejando una huella inigualable en su paso por el servicio de nefrología y en los pasillos del Hospital de San José. Nacido en Manizales en 1989, decide iniciar sus estudios de medicina y cirugía en la Universidad Nacional de Colombia, en donde igualmente cursa su primera especialización como médico internista, recibiendo dicho titulo en el memorable auditorio León de Greiff en 2018. Destacado galeno cursó su segunda especialidad en nuestro claustro, ingresando al programa de nefrología del Hospital de San José en 2019, en donde se destacó su integralidad, carisma, entrega y pasión por el arte de las ciencias clínicas y la nefrología.

Sus profesores Carlos Rosselli, Rodolfo Eduardo Torres, Orlando y Carlos Olivares, sus compañeros de residencia Maricely Reina, Diana Zambrano, Jean Carlos Heras, Jonth Flechas y Camilo Vallejo, así como todo el grupo de residentes del servicio de medicina interna del Hospital de San José, fuimos testigos del sobresaliente nivel académico, así como de sus intachables valores personales, aptitudes y habilidades que lo facultaban como la persona idónea para impartir conocimientos en los médicos que nos encontramos en formación e igualmente para llevar a término su subespecialidad.

Son lamentables las pérdidas que ha generado la lucha contra la pandemia de COVID-19 y aún más la partida de un ser integral como lo fue el Dr. Escobar, quien se mostró siempre fuerte y aguerrido para estar en pie de lucha ante los padecimientos de sus pacientes. A solo 6 meses de culminar su última meta, nos dejó, no sin antes haber demostrado su espíritu luchador, perseverante y emprendedor, que igualmente fueron ejemplo de enseñanza.

“...te has ido sin avisar, pero hoy vivo de los recuerdos felices que me dejaste..." Anónimo

A sus padres, el Dr. Lisímaco Escobar y señora Paula Castaño, sus hermanas Catalina y Paola Victoria y a su novia Luisa Nieto, nuestro mas sincero sentido pésame y solidaridad con esta devastadora pérdida, garantizando que mantendremos vivo el legado que ha marcado en cada uno de los que pudimos compartir espacios académicos y personales con él. Dr. Camilo, buen viaje...

"Esto no es un adiós, sino un gracias" - Nicholas Sparks

Sebastián M. Arenas MD. En nombre del grupo de residentes de medicina interna y nefrología, Hospital de San José y Fundación Universitaria de Ciencias de la Salud

\section{INFORMACIÓN DEL ARTÍCULO}

Historia del artículo:

Fecha recibido: agosto 30 de 2020

Fecha aceptado: agosto 31 de 2020
Autor para correspondencia.

Sebastian M. Arenas semaldonado@fucsalud.edu.co
DOI

10.31260/RepertMedCir.01217372.1111 